\title{
A STUDY TO EXPLORE PRESENCE OF SOCIAL SKILLS AMONG HEARING IMPAIRED STUDENTS
}

\author{
Abid Masood Khan*, Hifsa Batool $\uparrow \&$ Zabar Hussain $¥$
}

\begin{abstract}
Present study attempted to explore presence of social skills among hearing impaired students taking education from government special education schools and to compare different level of social skills based on different demographic variables. It is a descriptive study in nature and survey method is used to collect the data. Population of study is hearing impaired children living in division Faisalabad and Lahore. Sample of $N=200$ hearing impaired students are selected through convenient sampling technique. Responses of social skills are taken from mothers as mothers have better knowledge of proficiencies of their hearing impaired children's social skills. Children's age group was 05-20 years. Age range of mothers was 25-55 years. Social skills checklist was used to as tool of the study for collection of data. It is a mixed method approach and statistical measures were made via frequency distribution, $t$-test and ANOVA. Results of current study clearly depicted that $82 \%$ hearing impaired students have low level of social skills and $18 \%$ hearing impaired students have best level of social skills. Current study also find out that there is significant difference in social skills of students on the basis of living area and children age and there is no significant difference in presence of social skills in hearing impaired students based on mother's working status (house wife and job holders) and mothers education level. Study also demonstrated that there was positive correlation among presence of social skills in hearing impaired students and their age. The study concluded that teachers should focus on individual differences while teaching social skills to hearing impaired children and should adopt different teaching methods and teaching strategies for every student. It was also recommended that job holder mothers should manage
\end{abstract}

\footnotetext{
Govt. Special Education Department, Punjab, Pakistan. (abidmasood1986@gmail.com)

Govt. Special Education Department, Punjab, Pakistan. (hifsa763@gmail.com)

‡ Ph.D. Scholar, Allama Iqbal Open University, Islamabad. (zabar250@ gmail.com)
} 
their time table and must spare their proper time for their special children to make them beneficial and socially adjusted child of community.

Keywords: Social Skills, Hearing Impaired Children, Mothers

\section{Introduction}

It is very necessary and compulsory for every individual that they would be ready to face and compete with the challenges of life according to age, gender and disability wise according to cultural change and different incidents in the life. Person with disabilities may be preparing themselves in order to cope social changes, difficulties and the development of social dealings. For this purpose training is given to special students by the different psychologist and counselors though out schools years. To check emotional problems and social challenges, psychologists have involved themselves in social skills education in the whole world and the educational institutions on the suggestion of WHO \& UNICEF (WHO \& UNICEF, 2003). Social skills are the capacities which construct positive and valuable behavior, and these abilities make powerful to individuals to play out their social responsibilities and have ability to handle routine matter issues and maintain their relations without giving tension to him/her self or teasing others. Indeed, even normal children are thinking that it's hard to adapt up to the tricky circumstances, decision making in the everyday social life, as a student with hearing impairment experience gradually number of various issues in the playground, educational institutions and in the community. Life skills for the adjustment with the environment and living in the society with successful manners the trainings regarding social skills and life living skills must required (Gamst-Klaussen et al., 2016).

Social skill is a term used to portray a child's learning of, and the ability to employ, a mixture of social activities which are suitable to a spreading relational condition and that are fulfilling to other in every day circumstances. The ability to hinder egocentric, hasty or negative social behavior is additionally an impression of a child's social skills (Hoffman et al., 2015). There are many different social skills used by both hearing and hearing impaired children. These skills are used in different situations throughout the Child's day. Children start to absorb social skills since their birth. They are continually observing and copping the activities of their parents, siblings and society. A hearing impaired child's capacity to develop social skills will depend upon his severity of impairment, maturity and age of identification of problem, management and personality along with experiences they faced. In addition their exposure to variety of situations with hearing peers is also a combination of social skill development (Holstrum et al., 2008). Some of the social skills that children develop include; having peers, being friend, sharing of belongings, starting talk, 
fitting together in social groups, proper expressions of state of mind and identifying and taking suitable behavior. These skills can be taught by imitation, role play, social skills exercises, competitions, storytelling and written workshops (Patton, 2004).

The development of social skills is so important that for some children it is included in their IEPs. In these plans they are referred to as social integration goals and objectives. The child who having hearing loss is left untreated it can cause several secondary impairments. The hearing loss degrees or level and the age of child at onset, as well as his/her intellectual potential will influence the accumulation and magnitude of the secondary problem (Tharpe, 2008).

In this manner, evolving social skills improvement in disable children is the important or major role. The children those are hearing impaired are at more severe vulnerability for developmental delays and challenges than their friends with normal hearing. This risk is frequently playing a vital role in delays of their language. Yet the bilateral mild level hearing loss (26dB to $40 \mathrm{~dB}$ in the better ear) and mild level unilateral hearing loss (less than $25 \mathrm{~dB}$ in the better ear, above than $25 \mathrm{~dB}$ in the other ear) may take an extended risk of maladaptive improvement. All things considered, numerous results in the children having low level of hearing stay unexplored, especially those related through the emotionally and socially betterment (Winiger et al., 2016). To be sure, despite the fact that children with hearing disability are incorporated into certain studies, their social aptitudes have not been studied explicitly. This absence of learning reduces the planning of well-absorbed, positive intervention upsetting (Holstrum et al., 2008). As socially abilities acquiring is an essential developmental project in the early childhood education (Rose-Krasnor and Denham, 2009), the present investigation investigates these abilities in 5-15 year-old students having hearing impedance.

The present study investigates the presence of social skills among the children having hearing loss and their living situation and the status of their mother's education.

\section{Objectives of Study}

Following are the objectives of study:

1. To explore presence of social skills among hearing impaired students taking education from government special education schools.

2. To find out difference in presence of social skills of hearing impaired based on different demographics of mothers and children. 


\section{Questions of Study}

Following are the questions of study:

1. Do all hearing impaired students taking education from government special education schools have good level of social skills?

2. Is there significant difference in presence of social skills of hearing impaired based on different demographics?

\section{Methodology}

\section{Population and Sample of Study}

It is a descriptive study in nature and population of study is hearing impaired students taking education from government special education schools living in division Faisalabad and Lahore (Pakistan). Sample of $\mathrm{N}=200$ hearing impaired students are selected through convenient sampling technique. Delimitations of the study are those students taking education from government special education schools having both type of sibling (normal and hearing impaired) and also having hearing mother. Responses of social skills are taken from mothers as mothers have better knowledge of proficiencies of their hearing impaired children's social skills. Responses are not taken from the hearing impaired children due to communication problems, after using the sign language there were the chances of ambiguous responses so the mothers were called for data collection to get appropriate responses of social skills of children. The age of children ranges from 05-20 years and the mother's age range is $25-55$ years.

\section{Tool of Study}

\section{Social Skills Checklist (SSC):}

Social skills checklist (SSC) developed by researchers is used as tool of study. It is 40 items Likert type checklist and reliability of the checklist is 0.886. Social skills checklist comprised of 4 sections (social play, emotional development, and emotional regulation and communication skills). To achieve the objectives of current study researches considered combine all areas as social skills and did not work on them separately.

\section{Results}

Following are the results of study:

Frequency distribution of the data collected demonstrated that $82 \%$ hearing impaired children have low level of social skills and $18 \%$ hearing impaired children have good level of social skills. 
Overview of Social Skills Level Among the Students with Hearing Impairment on their Living Area (Rural/Urban) Basis

In this study, 100 Hearing Impaired Children were taken from rural residential areas and 100 Hearing Impaired Children were taken from urban living areas. It can be concluded that equal number of hearing impaired children were taken from both living location Urban and Rural to make comparison. This can be seen in the following table:

Table 1: Level of Social Skills among Hearing Impaired Children on the Basis of Their Living Area

\begin{tabular}{|c|c|c|c|c|c|}
\hline Living Area & $\boldsymbol{N}$ & $\boldsymbol{M}$ & $\boldsymbol{d} \boldsymbol{f}$ & $\boldsymbol{t}$ & $\boldsymbol{S i g}$ \\
\hline Rural & 100 & 48.43 & 198 & 2.356 & .019 \\
\hline Urban & 100 & 47.19 & & & \\
\hline
\end{tabular}

The level of significance is less than $.05=* P$

The above Table 1 indicated that there is significant difference in the level of social skills among hearing impaired children on the basis of their living area. It can be said that different living area (rural and urban) can affect the level of social skills among hearing impaired children.

\section{Overview of the Effects of Maternal Working Status on the Social Skills} Level of the Hearing Impaired Students

In this study, 64 mothers of children having hearing loss were doing jobs and 136 mothers of children having hearing loss were doing work in their houses. It can be concluded that the majority of the mothers of children having hearing loss were house wife's. This can be seen in the following table:

Table 2: Level of Social skills among Hearing Impaired Children on the Basis of their Maternal Working Status

\begin{tabular}{|l|c|c|c|c|c|}
\hline $\begin{array}{c}\text { Maternal Working } \\
\text { Status }\end{array}$ & $\boldsymbol{N}$ & $\boldsymbol{M}$ & $\boldsymbol{d f}$ & $\boldsymbol{t}$ & $\boldsymbol{S i g}$ \\
\hline Job Holder & 64 & 29.15 & 198 & -.424 & .470 \\
\hline House Wife & 136 & 29.39 & & & \\
\hline
\end{tabular}

The level of significance is less than $.05=* P$

The above Table 2 explored that there is no significant difference found in the level of social skills among hearing impaired children on the basis of their maternal working status. It can be said that different working status 
(house wife or job holder) of the mothers of hearing impaired children does not affect the level of social skills among hearing impaired children.

Overview of the Effects of Maternal Education Status on the Social Skills Level of the Hearing Impaired Students

In this study, mothers of children with hearing impairment have different levels of education. It can be concluded that $26 \%$ mothers are under Matric, 33\% are Matric pass and $41 \%$ of the mothers of children with hearing loss having Bachelor degree. This can be seen in the following table:

Table 3: Level Of Social Skills among Hearing Impaired Children on The Basis of their Maternal Education

\begin{tabular}{|l|c|c|c|c|c|}
\hline \multicolumn{1}{|c|}{ Groups } & $\begin{array}{c}\text { Sum of } \\
\text { Squares }\end{array}$ & df & $\begin{array}{c}\text { Mean } \\
\text { Square }\end{array}$ & $\boldsymbol{F}$ & Sig \\
\hline Between Groups & 572.642 & 2 & 114.528 & 1.366 & .247 \\
\hline Within Groups & 6289.975 & 197 & 83.866 & & \\
\hline
\end{tabular}

The level of significance is less than $.05=* P$

The above Table 3 showed that there is no significant difference found in the level of social skills among hearing impaired children on the basis of their maternal education. It can be said that maternal education of hearing impaired children does not affect the level of social skills among hearing impaired children.

Overview of Social Skills among the Students with Hearing Impairment on the Basis of their Age

In this study, hearing impaired children having different age were participated. It can be concluded that $15 \%$ of hearing impaired children having age $05-10$ Years, $65 \%$ of hearing impaired children having age 10-15 years and $20 \%$ of the hearing impaired children having age $16-20$ years. This can be seen in the following table:

Table 4: Level of Social Skills among Hearing Impaired Children on the Basis of their Age

\begin{tabular}{|c|c|c|c|c|c|}
\hline \multicolumn{1}{|c|}{ Groups } & $\begin{array}{c}\text { Sum of } \\
\text { Squares }\end{array}$ & df & $\begin{array}{c}\text { Mean } \\
\text { Square }\end{array}$ & F & Sig \\
\hline Between Groups & 147.944 & 2 & 73.97 & 2.50 & .043 \\
\hline Within Groups & 4632.831 & 197 & 29.50 & & \\
\hline
\end{tabular}

The level of significance is less than $.05=* P$ 
The above Table 4 indicated that there is significant difference in the level of social skills among hearing impaired children on the basis of their age. It can be said that different age level can affect the level of social skills among hearing impaired children.

\section{Description of Relationship among Social Skills and the Age of Hearing Impaired Children}

In this study, the children with hearing loss having different age level were participated. It can be concluded that the positive relation found among social skills and the age of children having hearing loss. This can be seen in the following table:

\section{Table 5: Relationship among Social Skills and the Age of Hearing Impaired Children}

\begin{tabular}{|c|l|c|c|}
\hline \multicolumn{2}{|c|}{} & Social skills & Age \\
\hline \multirow{4}{*}{ Social skills } & Pearson Correlation & 1 & $.626^{* *}$ \\
\cline { 2 - 4 } & Sig. (2-tailed) & & .001 \\
\cline { 2 - 4 } & $\mathrm{N}$ & 100 & 100 \\
\hline \multirow{4}{*}{ Age } & Pearson Correlation & $.626^{* *}$ & 1 \\
\cline { 2 - 4 } & Sig. (2-tailed) & .001 & 100 \\
\cline { 2 - 4 } & $\mathrm{N}$ & 100 & \\
\hline
\end{tabular}

**The correlation is significant at the level of 0.01 (2-tailed).

Above table explored that positive correlations is found in the social skills and the age of children with hearing loss. The age of the children with hearing loss has positive relation with the social abilities or gets of children with hearing loss.

\section{Discussion}

In general, hearing impaired children display lower social aptitude, including social skills, than normal hearing children. Hoffman et al. (2015) reported lower social competency among the children with hearing loss having the hearing loss from severe to profound level matched or compared with the children having normal hearing. The same findings or results was concluded in the researches of cochlear implants children and the children having mild level hearing loss to profound level hearing loss (Wiefferink et al., 2012). However, exemptions do happen; age-suitable socially skills were 
described between the hearing impaired students having mild level hearing loss to profound level hearing loss and the children with cochlear implants (Ketelaar et al., 2013). The researches that found impediments and those reporting age-suitable improvement do not vary around the degrees of hearing loss or the participants age level but the exercise of many assessment techniques and the merger of children having all hearing loss degree levels in the same sample may also conclude to the unpredictability in results.

\section{Findings and Conclusion}

It is found out that $82 \%$ hearing impaired students have low level of social skills and $18 \%$ hearing impaired students have best level of social skills. Current study also found out that there is significant difference in social skills of students living in urban and rural areas and there is no significant difference in presence of social skills in hearing impaired students based on mother's education and working status (housewife and jobholders). It is found out that there is positive correlation among presence of social skills in hearing impaired students and their age. We can conclude from findings of current study that teachers should focus on individual differences while teaching social skills to hearing impaired children and should adopt different teaching methods and teaching strategies for every student. Findings of current study set a question mark for all the policy makers' teachers and parents of hearing impaired children that why mostly of hearing impaired children are not good in their social skills. Deficiency in presence of social skills can become a big hurdle in rehabilitation of hearing impaired. It is also recommended that job holder mothers should manage their time table and must spare their few quality of time for their special children to make them beneficial and socially adjusted child of community.

The present study has its implications for teachers, educational administrators, curriculum framers and parents. The first responsibility of the parents and teachers should be to know the areas where the students lack skills and try to give better conditions for proper skills in every sphere. The school should provide facilities to special needs children for their better skills and on the basis of current study it is recommended that policy makers and school administration should make arrangements for uplifting social skills among special needs children and workshops and seminars should be arranged at government and semi-government level for the enhancement of skills and rehabilitation of special needs children. 


\section{References}

Gamst-Klaussen, T., Rasmussen, L.M.P., Svartdal, F. \& Strømgren, B. (2016). Comparability of the social skills improvement system to the social skills rating system: a Norwegian study. Scandinavian journal of educational research, 60(1), 20-31.

Hoffman, M.F., Quittner, A.L. \& Cejas, I. (2014). Comparisons of social competence in young children with and without hearing loss: A dynamic systems framework. Journal of Deaf Studies and Deaf Education, 20(2), 115-124.

Holstrum, W.J., Gaffney, M., Gravel, J.S., Oyler, R.F. \& Ross, D.S. (2008). Early intervention for children with unilateral and mild bilateral degrees of hearing loss. Trends in Amplification, 12(1), 35-41.

Keilmann, A., Limberger, A. \& Mann, W.J. (2007). Psychological and physical well-being in hearing-impaired children. International journal of pediatric otorhinolaryngology, 71(11), 1747-1752.

Ketelaar, L., Rieffe, C., Wiefferink, C.H. \& Frijns, J.H. (2013). Social competence and empathy in young children with cochlear implants and with normal hearing. The laryngoscope, 123(2), 518-523.

Lee, A., Hankin, B.L. \& Mermelstein, R.J. (2010). Perceived social competence, negative social interactions, and negative cognitive style predict depressive symptoms during adolescence. Journal of clinical child \& adolescent psychology, 39(5), 603-615.

Patton, R.K. (2004). Social skills issues of mainstreaming hearing-impaired children.

Rose-Krasnor, L. \& Denham, S. (2009). Social-emotional competence in early childhood. Handbook of peer interactions, relationships, and groups, 162-179.

Tharpe, A.M. (2008). Unilateral and mild bilateral hearing loss in children: past and current perspectives. Trends in amplification, 12(1), 7-15.

Wiefferink, C.H., Rieffe, C., Ketelaar, L., De Raeve, L. \& Frijns, J.H. (2012). Emotion understanding in deaf children with a cochlear implant. Journal of deaf studies and deaf education, 18(2), 175-186.

Winiger, A.M., Alexander, J.M. \& Diefendorf, A.O. (2016). Minimal hearing loss: From a failure-based approach to evidence-based practice. American journal of audiology, 25(3), 232-245.

World Health Organization. (2003). Skills for health: skills-based health education including life skills: an important component of a childfriendly/health-promoting school. 